\title{
Emerging drug combinations to optimize renovascular protection and blood pressure goals
}

This article was published in the following Dove Press journal: International Journal of Nephrology and Renovascular Disease 2 April 2012

Number of times this article has been viewed

\author{
Carlos Escobar ${ }^{1}$ \\ Rocio Echarri² \\ Vivencio Barrios ${ }^{3}$ \\ 'Department of Cardiology, \\ Hospital Infanta Sofía, Madrid, \\ Spain; ${ }^{2}$ Department of Nephrology, \\ Hospital Infanta Sofía, Madrid, Spain; \\ ${ }^{3}$ Department of Cardiology, Hospital \\ Ramón y Cajal, Madrid, Spain
}

Correspondence: Vivencio Barrios Department of Cardiology, Hospital Ramón y Cajal, Madrid 28034, Spain Fax +34 91 3368665 Email vbarriosa@meditex.es; vbarrios.hrc@salud.madrid.org

\begin{abstract}
Hypertension and renal disease are closely related. In fact, there is an inverse linear relationship between renal function and prevalence of hypertension. Hypertensive patients with renal dysfunction exhibit a poor clinical profile, which markedly increases their risk for cardiovascular outcomes. This review considers the available evidence on the best therapeutic approach for optimizing renovascular protection in the hypertensive population. To effectively reduce or at least slow the establishment and progression of renal disease in the hypertensive population it is critical to reach blood pressure targets. Many studies have shown that angiotensinconverting enzyme inhibitors and angiotensin receptor blockers prevent or at least delay the development of microalbuminuria in patients with hypertension and type 2 diabetes, reduce the incidence of overt diabetic nephropathy, and are also beneficial in patients with nondiabetic renal disease. Therefore, renin-angiotensin system (RAS) inhibition plays a key role in the prevention of renal outcomes. As the majority of patients with hypertension will need at least two antihypertensive agents to achieve blood pressure goals, the use of RAS inhibitors is a mandatory part of antihypertensive therapy. The question of which antihypertensive agent is the best choice for combining with RAS blockers should be considered. Many studies have shown that diuretics and calcium channel blockers are the best choice. However, more studies are needed to clarify the subgroups of patients who will benefit more from a combination with a diuretic or from a combination with a calcium channel blocker. To date, RAS inhibitors recommended in this context are angiotensin-converting enzyme inhibitors and angiotensin receptor blockers. Aliskiren, the first oral direct renin inhibitor available, has shown promising results.

Keywords: antihypertensive drugs, renin-angiotensin system, angiotensin-converting enzyme inhibitors, angiotensin receptor blockers, combined therapy
\end{abstract}

\section{Hypertension and renal disease}

Hypertension is the most important modifiable risk factor for cardiovascular disease. It has been estimated that about $30 \%$ of the general population is hypertensive, a proportion that increases to two-thirds in the elderly. ${ }^{1}$ Remarkably, this prevalence is increased in patients with renal insufficiency. Thus, in a large cohort of Spanish patients enrolled in an ongoing prospective, observational, multicenter study of patients with stage $3(n=434)$ and $4(n=695)$ chronic kidney disease, hypertension was almost universal (91.2\% and 94.1\%, respectively). Moreover, proteinuria ( $>300 \mathrm{mg} /$ day) was present in more than $60 \%$ of patients, without significant differences between stages 3 and $4\left(1.2 \pm 1.8\right.$ and $1.3 \pm 1.8 \mathrm{~g}$ /day, respectively). ${ }^{2}$ In fact, there is an inverse linear relationship between renal function and prevalence of hypertension (from $66 \%$ at a glomerular filtration rate of $83 \mathrm{~mL} /$ minute per $1.73 \mathrm{~m}^{2}$ of body surface area to $95 \%$ at 
a glomerular filtration rate of $12 \mathrm{~mL} /$ minute per $1.73 \mathrm{~m}^{2}$ of body surface area). ${ }^{3}$ In patients with diabetic nephropathy, the prevalence of hypertension ranges from $41 \%$ in subjects with type 1 diabetes to $93 \%$ in those with type 2 diabetes and proteinuria. ${ }^{4,5}$ Therefore, hypertension and kidney health are closely related. Hypertension is one of the main causes of renal disease, and hypertension is more prevalent in patients with a decreased renal function. ${ }^{6}$

There is an inverse relationship between renal function and the risk of cardiovascular disease. ${ }^{7}$ This relationship was first demonstrated in patients with end-stage renal disease. Thus, about $40 \%-75 \%$ of patients on dialysis have cardiovascular disease, and around $50 \%$ of these patients die from this condition. Overall, patients with end-stage renal disease have an increased risk, up to 20-30 times, of developing cardiovascular disease when compared with the general population. ${ }^{8-11}$ There is also a clear relationship between moderate renal disease and cardiovascular disease. In the HOPE (Heart Outcomes and Prevention Evaluation) study, ramipril significantly reduced the rates of death, myocardial infarction, and stroke in a broad range of high-risk patients who were not known to have a low ejection fraction or heart failure. In a post hoc analysis, the risk of myocardial infarction was higher for patients with a baseline serum creatinine level $\geq 1.4 \mathrm{mg} / \mathrm{dL}(\mathrm{n}=980)$ than for those with a serum creatinine level $<1.4 \mathrm{mg} / \mathrm{dL}(\mathrm{n}=8307) .{ }^{12}$ In the Hypertension Optimal Treatment study involving 18,597 patients, at baseline there were 470 patients who had a serum creatinine level higher than $1.5 \mathrm{mg} / \mathrm{dL}$. Those patients with a high serum creatinine level at randomization more frequently had a history of myocardial infarction or other sequelae of coronary heart disease, stroke, and diabetes mellitus than those with a serum creatinine level $\leq 1.5 \mathrm{mg} / \mathrm{dL} .{ }^{13}$ Moreover, cardiac structure alterations are more frequent in patients with renal insufficiency. Thus, left ventricular hypertrophy is more common in subjects with a creatinine clearance $<30 \mathrm{~mL} /$ minute $(38 \%)$ than in those with a creatinine clearance $>30 \mathrm{~mL} /$ minute $(16 \%){ }^{14}$

Furthermore, hypertensive patients with renal dysfunction exhibit a poor clinical profile, which markedly increases their risk for cardiovascular outcomes. Thus, in a study involving 2024 patients with hypertension and chronic ischemic heart disease, those patients with an estimated glomerular filtration rate (using the Modification of Diet in Renal Disease study formula) $<60 \mathrm{~mL} /$ minute per $1.73 \mathrm{~m}^{2}$ of body surface area ( $n=666 ; 32.9 \%$ ) were older and had a higher proportion of atrial fibrillation, diabetes, organ damage (left ventricular hypertrophy), associated clinical conditions (heart failure, cerebrovascular disease), and worse blood pressure (BP) control rates. ${ }^{15}$

The diagnosis of hypertension-induced renal damage in hypertensives is based not only on reduced renal function but also on increased urinary excretion of albumin. ${ }^{11}$ This is very relevant, as it is well established that any degree of albuminuria is associated with a higher risk of cardiovascular disease and progression of kidney disease. In fact, there is a continuous relationship between urinary albumin excretion and cardiovascular disease. ${ }^{16-18}$ Therefore, a reduced glomerular filtration rate and an increased urinary albumin excretion markedly raise cardiovascular risk, particularly so when both alterations are present. ${ }^{19}$ As a result, the prevention of development of either microalbuminuria or renal dysfunction are two essential targets in patients with hypertension. ${ }^{1,11}$

\section{Importance of BP control}

Hypertension is related not only to the development but also to the progression of renal disease. Several studies have analyzed the factors influencing the progression to chronic renal disease. Although many factors such as age, male gender, $\mathrm{HbA1c}$ in diabetics, smoking, obesity or hypercholesterolemia have been involved, BP control and proteinuria are the most important. ${ }^{20-22}$ In the Multiple Risk Factor Intervention Trial, which involved 332,544 men between the ages of 35 and 57 years who were screened between 1973 and 1975, after a 16-year follow-up 814 subjects had either died of endstage renal disease or were being treated for that condition (15.6 cases per 100,000 person-years of observation). A strong, graded relationship between both systolic and diastolic BP and end-stage renal disease was identified. Moreover, as compared with men with an optimal level of $\mathrm{BP}(<120 / 80 \mathrm{mmHg})$, the relative risk of end-stage renal disease for those with higher BP values $(\geq 210 / 120 \mathrm{mmHg})$ was $22.1(P<0.001) .{ }^{23}$ In a US study performed in California, after 8,210,431 personyears of follow-up, and on 316,675 subjects with an estimated glomerular filtration rate $\geq 60 \mathrm{~mL} /$ minute per $1.73 \mathrm{~m}^{2}$ of body surface area and negative dipstick urinalysis results for proteinuria or hematuria, 1149 cases of end-stage renal disease occurred. Compared with subjects with a BP $<120 / 80 \mathrm{mmHg}$, the relative risks for developing end-stage renal disease were 1.62 for BP of 120-129/80-84 $\mathrm{mmHg}, 1.98$ for BP of 130-139/85-89 $\mathrm{mmHg}, 2.59$ for BP of 140-159/90$99 \mathrm{mmHg}, 3.86$ for BP of 160-179/100-109 $\mathrm{mmHg}, 3.88$ for BP of 180-209/110-119 $\mathrm{mmHg}$, and 4.25 for BP of $\geq 210 / 120 \mathrm{mmHg}$. ${ }^{22}$ With regard to BP components, it has been observed that systolic BP is a stronger predictor of endstage renal disease than diastolic BP or pulse pressure. ${ }^{24}$ 
The Modification of Diet in Renal Disease study examined the effects of dietary protein restriction and strict BP control on the decline in glomerular filtration rate in 840 patients with diverse renal diseases. In the multivariate analysis, six factors (greater urine protein excretion, diagnosis of polycystic kidney disease, lower serum transferrin, higher mean arterial pressure, black ethnicity, and lower serum high-density lipoprotein cholesterol) independently predicted a faster decline in glomerular filtration rate. A low BP intervention was found to have greater benefit in patients with higher levels of baseline urine protein. ${ }^{20}$ Different meta-analyses have shown in diabetics and nondiabetics that BP control slows progression of renal disease. ${ }^{25,26} \mathrm{~A}$ meta-analysis by Jafar et $\mathrm{al}^{26}$ analyzed eleven randomized controlled trials comparing the efficacy of antihypertensive regimens with or without angiotensin-converting enzyme (ACE) inhibitors for patients with predominantly nondiabetic kidney disease. The paper reported that a systolic BP goal between 110 and $129 \mathrm{mmHg}$ may be beneficial in patients with urine protein excretion levels greater than $1.0 \mathrm{~g} /$ day. However, a systolic BP $<110 \mathrm{mmHg}$ may be associated with a higher risk of kidney disease progression. ${ }^{26}$

All these data emphasize the importance of attaining BP goals in the hypertensive population to avoid or at least slow the development or progression of renal disease. The question of what the BP goals should be, not only in the overall hypertensive population but also in high-risk patients, should be considered. The 2007 European Society of HypertensionEuropean Society of Cardiology guidelines for the management of arterial hypertension established that BP should be reduced to at least $<140 / 90 \mathrm{mmHg}$, and to lower values, if tolerated, in all hypertensive patients. Target BP should be at least $<130 / 80 \mathrm{mmHg}$ in diabetics and in high- or veryhigh-risk patients, such as those with associated clinical conditions (stroke, myocardial infarction, renal dysfunction, proteinuria). ${ }^{1}$ The reappraisal of European guidelines, published in 2009, indicates that there is sufficient evidence to recommend a BP goal below 140/90 mmHg in each hypertensive patient. However, on the basis of current data, it may be prudent to recommend lowering BP to values within the range $130-139 / 80-85 \mathrm{mmHg}$, and possibly closer to the lower values in this range, in every hypertensive. ${ }^{27}$ National Institute for Health and Clinical Excellence guidelines recommend a BP goal $<140 / 90 \mathrm{mmHg}$ in the overall hypertensive population and $<140 / 80 \mathrm{mmHg}$ in diabetics (or $<130 / 80 \mathrm{mmHg}$ if kidney, eye, or cerebrovascular damage is present). ${ }^{28}$ The Canadian guidelines establish that in hypertensive patients without other compelling indications, the BP goal should be $<140 / 90 \mathrm{mmHg}$, as well as in hypertensive patients with a history of cardiovascular disease (coronary artery disease, previous myocardial infarction, heart failure, left ventricular hypertrophy, past stroke/transient ischemic attack or peripheral arterial disease). In patients with diabetes with/ without albuminuria, nondiabetic chronic kidney disease with proteinuria or renovascular disease, the target BP should be $<130 / 80 \mathrm{mmHg} .{ }^{29}$

A recent systematic review analyzed what should be the optimal BP target in patients with chronic kidney disease. For this purpose, three trials with a total of 2272 participants were included. Overall, trials did not show that a BP target $<125 / 75-130 / 80 \mathrm{mmHg}$ was more beneficial than a target of $<140 / 90 \mathrm{mmHg}$. Lower-quality evidence suggested that a lower target may be beneficial in subgroups with proteinuria $>300-1000 \mathrm{mg} /$ day. ${ }^{30}$

Although BP control rates have improved in recent years, there remains a lot of room for improvement. One of the most important reasons for the recent improvements shown is the higher use of combined therapy. On the other hand, as cardiovascular risk increases, a smaller proportion of patients attain BP goals, including those with renal dysfunction (Table 1). ${ }^{31-33}$

\section{Renin-angiotensin system inhibition and renovascular protection}

Although the renin-angiotensin-aldosterone system (RAS) plays a critical role in human physiology, and although angiotensin II, the RAS effector peptide, is essential for the homeostatic control of the cardiovascular system (including, among others, sodium and water balance, BP control, and cellular growth and replication), the excessive RAS activation is markedly associated with the establishment and progression of the cardiovascular continuum. ${ }^{6,34,35}$ In fact, the excessive activation of the RAS has been implied in the progression of the entire cardiovascular disease continuum, from the early

Table I Percentage of patients who attain blood pressure (BP) goals according to cardiovascular risk and clinical profile

\begin{tabular}{llllllll}
\hline \multicolumn{7}{l}{ Hypertensive population attended daily by primary care physicians } & \\
\hline Clinical condition & Low risk & Medium risk & High risk & Diabetes & Metabolic syndrome & Cardiovascular disease & Cardiac disease \\
\hline BP control rates & $37.5 \%$ & $30.2 \%$ & $15.4 \%$ & $6.3 \%$ & $17.2 \%$ & $25.3 \%$ \\
\hline
\end{tabular}

Note: Data from the PRESCOT (Prevención Cardiovascular en España en Atención Primaria: Intervención Sobre el Colesterol en Hipertensión) study (adapted from Barrios ${ }^{32}$ ). 
stages (hypertension and diabetes) to the middle (left ventricular hypertrophy and microalbuminuria) and late stages (coronary disease, stroke, heart failure, and renal disease). ${ }^{6}$

In the case of the kidneys, at the beginning, and through different mechanisms such as oxidative stress, angiotensin II promotes subclinical damage to glomerular endothelium that results in endothelial dysfunction. Thereafter, because of vascular sclerosis and the glomerulosclerosis, tubulointerstitial fibrosis, which implies a progressive deterioration of the glomerular capillary barrier and the hemodynamic abnormalities in the vasculature at the glomerular level, microalbuminuria appears. As a result, microalbuminuria is an early manifestation of renal damage in patients with hypertension, particularly in diabetics. If treatment is not applied, renal damage progresses to macroalbuminuria or proteinuria. In this context, the glomerular filtration rate progressively declines to the final stages of renal disease. This gradual decline in renal function is associated with an increased risk of cardiovascular disease. Therefore, excess angiotensin II production is responsible, at least in part, for the establishment and development of hypertension and renal damage. ${ }^{6,35-37}$

However, despite the knowledge about the importance of the RAS in the development of cardiovascular disease provided, at least in part, from experimental data, and despite the fact that high renin activity is associated with cardiovascular outcomes, the most robust evidence has come from clinical trials using ACE inhibitors, angiotensin receptor blockers (ARBs) and, in recent years, aliskiren - the first oral direct renin inhibitor. ${ }^{6,38-40}$

Some trials have analyzed the effects of RAS inhibition in the prevention of microalbuminuria in patients with hypertension and type 2 diabetes. The BENEDICT (Bergamo Nephrologic Diabetes Complications Trial) study reported that in subjects with type 2 diabetes and hypertension but with normoalbuminuria, the use of trandolapril plus verapamil (5.7\%) and trandolapril alone $(6.0 \%)$ decreased the incidence of microalbuminuria to a similar extent. However, the effect of verapamil alone (11.9\%) was similar to that of placebo $(10.0 \%) .{ }^{41}$ In the ROADMAP (Randomized Olmesartan and Diabetes Microalbuminuria Prevention) study, 4447 patients with type 2 diabetes and normoalbuminuria were randomized to receive olmesartan (at a dose of $40 \mathrm{mg}$ once daily) or placebo for a median of 3.2 years. Additional antihypertensive drugs (except ACE inhibitors or ARBs) were used as needed to lower $\mathrm{BP}$ to $<130 / 80 \mathrm{mmHg}$. The main results of this study showed that the target BP $(<130 / 80 \mathrm{mmHg})$ was achieved in nearly $80 \%$ of the patients taking olmesartan and in $71 \%$ of those taking placebo (clinic BP was 3.1/1.9 mmHg lower in the olmesartan group than in the placebo group). Microalbuminuria developed in $8.2 \%$ of the patients in the olmesartan group and in $9.8 \%$ of those in the placebo group. Moreover, the time to the onset of microalbuminuria was increased by $23 \%$ with the ARB olmesartan (hazard ratio [HR], 0.77; 95\% confidence interval [CI], 0.63-0.94; $P=0.01$ ) (Table 2). ${ }^{42}$

Both ACE inhibitors and ARBs have been shown to reduce the incidence of overt diabetic nephropathy. Thus, in the 3577 people with diabetes included in the HOPE study, ramipril reduced the risk of overt nephropathy by $24 \%$ $(P=0.027)$ when compared with placebo, and this effect was greater than that attributable to the decrease in $\mathrm{BP} .{ }^{43}$ In the Irbesartan in Patients with Type 2 Diabetes and Microalbuminuria study, irbesartan was shown to be renoprotective independently of its BP-lowering effect in patients with type 2 diabetes and microalbuminuria. ${ }^{44}$ In the RENAAL (Reduction of Endpoints in Non-Insulin-Dependent Diabetes Mellitus with the Angiotensin II Antagonist Losartan) trial, 1513 patients with type 2 diabetes and nephropathy were randomized to receive losartan (50-100 mg once daily) or placebo, both taken in addition to conventional antihypertensive treatment. Over a mean treatment period of 3.4 years, the composite primary end point of a doubling of serum creatinine concentration, end-stage renal disease, or death occurred in 327 and 359 patients assigned to losartan and placebo, respectively (risk reduction, $16 \%$; $95 \%$ CI, 2\%-28\%; $P=0.02) .{ }^{45}$ The Irbesartan in Diabetic Nephropathy Trial compared the renoprotective efficacy of irbesartan $300 \mathrm{mg}$, amlodipine $10 \mathrm{mg}$, and placebo in 1715 hypertensive patients with nephropathy caused by type 2 diabetes. Over the mean follow-up period of 2.6 years, irbesartan reduced the risk of the primary end point (doubling of serum creatinine concentration, end-stage renal disease, or death) by $20 \%$ when compared with placebo and by $23 \%$ when compared with amlodipine. The risk of a doubling of the serum creatinine concentration was $33 \%$ and $37 \%$ lower with irbesartan than with placebo and amlodipine, respectively, and irbesartan also reduced the risk of endstage renal disease by $23 \%$ compared with either placebo or amlodipine. ${ }^{46}$ More recently, the ORIENT (Olmesartan Reducing Incidence of End Stage Renal Disease in Diabetic Nephropathy Trial) study examined the effects of olmesartan on the primary composite outcome of doubling serum creatinine concentration, end-stage renal disease, and death in type 2 diabetic patients with overt nephropathy. A total of 577 patients treated with antihypertensive therapy (73.5\% received concomitant ACE inhibitors) were 
Table 2 Relevant studies that have studied the effects of renin-angiotensin system inhibition on renal outcomes

\begin{tabular}{|c|c|c|c|}
\hline Clinical setting & Study & Population & Commentary \\
\hline \multirow[t]{2}{*}{$\begin{array}{l}\text { Prevention of microalbuminuria } \\
\text { in patients with hypertension } \\
\text { and type } 2 \text { diabetes }\end{array}$} & BENEDICT ${ }^{41}$ & $\begin{array}{l}\text { Subjects with type } 2 \text { diabetes } \\
\text { and hypertension but with } \\
\text { normoalbuminuria }\end{array}$ & $\begin{array}{l}\text { The use of trandolapril plus verapamil }(5.7 \%) \\
\text { and trandolapril alone }(6.0 \%) \text { decreased the incidence } \\
\text { of microalbuminuria to a similar extent } \\
\text { The effect of verapamil alone ( } 11.9 \%) \text { was similar } \\
\text { to that of placebo }(10.0 \%)\end{array}$ \\
\hline & ROADMAP ${ }^{42}$ & $\begin{array}{l}\text { Patients with type } 2 \text { diabetes } \\
\text { and normoalbuminuria }\end{array}$ & $\begin{array}{l}\text { Microalbuminuria developed in } 8.2 \% \text { of the patients } \\
\text { in the olmesartan group and } 9.8 \% \text { in the placebo group } \\
\text { Time to the onset of microalbuminuria was increased } \\
\text { by } 23 \% \text { with olmesartan (HR, } 0.77 ; P=0.01 \text { ) }\end{array}$ \\
\hline \multirow[t]{6}{*}{$\begin{array}{l}\text { Reduction of overt diabetic } \\
\text { nephropathy }\end{array}$} & $\mathrm{HOPE}^{43}$ & $\begin{array}{l}\text { Patients of HOPE } \\
\text { with diabetes }\end{array}$ & $\begin{array}{l}\text { Ramipril reduced the risk of overt nephropathy } \\
\text { by } 24 \%(P=0.027) \text { when compared with placebo }\end{array}$ \\
\hline & IRMA2 ${ }^{44}$ & $\begin{array}{l}\text { Patients with type } 2 \text { diabetes } \\
\text { and microalbuminuria }\end{array}$ & $\begin{array}{l}\text { Irbesartan was shown to be renoprotective independently } \\
\text { of its BP-lowering effect }\end{array}$ \\
\hline & RENAAL 45 & $\begin{array}{l}\text { Patients with type } 2 \text { diabetes } \\
\text { and nephropathy }\end{array}$ & $\begin{array}{l}\text { The composite primary end point of doubling of serum } \\
\text { creatinine concentration, end-stage renal disease, } \\
\text { or death was reduced with losartan when compared } \\
\text { with placebo (risk reduction, } 16 \% ; P=0.02 \text { ) }\end{array}$ \\
\hline & $\mathrm{IDNT}^{46}$ & $\begin{array}{l}\text { Hypertensive patients with } \\
\text { type } 2 \text { nephropathy diabetes }\end{array}$ & $\begin{array}{l}\text { Irbesartan reduced the risk of the primary end point } \\
\text { (doubling of serum creatinine concentration, end-stage } \\
\text { renal disease, or death) by } 20 \% \text { and } 23 \% \text {, compared } \\
\text { with placebo and amlodipine, respectively }\end{array}$ \\
\hline & ORIENT ${ }^{47}$ & $\begin{array}{l}\text { Type } 2 \text { diabetic patients with } \\
\text { overt nephropathy }\end{array}$ & $\begin{array}{l}\text { Olmesartan did not improve renal outcome on top } \\
\text { of ACE inhibitors }\end{array}$ \\
\hline & AVOID $^{40}$ & $\begin{array}{l}\text { Hypertensive patients with } \\
\text { type } 2 \text { diabetic nephropathy }\end{array}$ & $\begin{array}{l}\text { Despite a small, not statistically significant difference } \\
\text { in BP between groups, aliskiren reduced the mean } \\
\text { urinary albumin-to-creatinine ratio by } 20 \%(P<0.00 \text { I })\end{array}$ \\
\hline Nondiabetic renal disease & $\mathrm{ROAD}^{51}$ & $\begin{array}{l}\text { Patients with nondiabetic } \\
\text { chronic renal insufficiency }\end{array}$ & $\begin{array}{l}\text { Optimal antiproteinuric dosages of benazepril and losartan } \\
\text { at comparable BP control, achieved a greater reduction } \\
\text { in both proteinuria and the rate of decline in renal function } \\
\text { than with their conventional dosages }\end{array}$ \\
\hline
\end{tabular}

Abbreviations: ACE, angiotensin-converting enzyme; AVOID, Aliskiren in the Evaluation of Proteinuria in Diabetes; BENEDICT, Bergamo Nephrologic Diabetes Complications Trial; BP, blood pressure; HOPE, Heart Outcomes and Prevention Evaluation; HR, hazard ratio; IDNT, Irbesartan in Diabetic Nephropathy Trial; IRMA2, Irbesartan in Patients with Type 2 Diabetes and Microalbuminuria; ORIENT, Olmesartan Reducing Incidence of End Stage Renal Disease in Diabetic Nephropathy Trial; RENAAL, Reduction of Endpoints in Non-Insulin-Dependent Diabetes Mellitus with the Angiotensin Il Antagonist Losartan; ROAD, Renoprotection of Optimal Antiproteinuric Doses; ROADMAP, Randomized Olmesartan and Diabetes Microalbuminuria Prevention.

included. Although olmesartan was well tolerated, it did not improve renal outcome on top of ACE inhibitors. ${ }^{47}$ Aliskiren, the last marketed RAS inhibitor, has also been tested in this context. ${ }^{48}$ Thus, the AVOID (Aliskiren in the Evaluation of Proteinuria in Diabetes) trial was performed to assess the renoprotective effects of dual blockade of the RAS by adding treatment with aliskiren to the maximally recommended dose of losartan (100 mg daily) and optimal antihypertensive therapy in hypertensive patients with type 2 diabetic nephropathy. Despite a small, not statistically significant difference in BP between groups $(-2 /-1 \mathrm{mmHg}$ lower in the aliskiren group), aliskiren reduced the mean urinary albumin-to-creatinine ratio by $20 \%(P<0.001)$ (Table 2). ${ }^{40}$

Some studies have been developed in patients with nondiabetic renal disease. Thus, it has been observed that in microalbuminuric subjects, treatment with fosinopril has a significant effect on urinary albumin excretion. ${ }^{49}$ In a study performed in patients with chronic nephropathies with proteinuria $\geq 3 \mathrm{~g} /$ day, ramipril safely reduced proteinuria and the rate of glomerular filtration rate decline to an extent that seemed to exceed the reduction expected for the degree of BP lowering. ${ }^{50}$ The ROAD (Renoprotection of Optimal Antiproteinuric Doses) study was aimed to determine whether titration of benazepril or losartan to optimal antiproteinuric doses would safely improve the renal outcome in nondiabetic chronic renal insufficiency. The study showed that optimal antiproteinuric dosages of benazepril and losartan, at comparable BP control, achieved a greater reduction in both proteinuria and the rate of decline in renal function than their conventional dosages (Table 2). ${ }^{51}$

In the ONTARGET (Ongoing Telmisartan Alone and in Combination with Ramipril Global Endpoint Trial) study, telmisartan was clinically equivalent to ramipril in patients 
with vascular disease or high-risk diabetes. ${ }^{52}$ In a substudy that specifically analyzed renal outcomes, the composite primary outcome (a composite of dialysis, doubling of serum creatinine concentration, and death) was similar for telmisartan and ramipril (13.4\% versus $13.5 \%$, respectively; HR, 1.00; 95\% CI, 0.92-1.09). The secondary renal outcome, dialysis or doubling of serum creatinine concentration, was also similar for telmisartan and ramipril $(2.21 \%$ versus $2.03 \%$; HR, 1.09; 95\% CI, 0.89-1.34). The estimated glomerular filtration rate declined least with ramipril compared with telmisartan, but the increase in urinary albumin excretion was smaller with telmisartan than with ramipril. ${ }^{53}$

Although there are unquestionable benefits of RAS inhibition in the prevention of renal complications in the hypertensive population (particularly in diabetics), the majority of patients with hypertension, especially those at highest risk, will need at least two antihypertensive drugs to attain BP goals. ${ }^{1,33}$ So, since RAS inhibitors are an essential component of combined therapy, the next question to be considered is which antihypertensive drug should be associated with RAS inhibitors to better prevent or at least delay renal outcomes.

\section{Combination of RAS inhibitors and diuretics}

Diuretics (usually thiazides or thiazide-like indoline diuretics such as indapamide) have been shown to effectively reduce BP levels. ${ }^{54}$ Moreover, in the 13,101 hypertensive patients with type 2 diabetes enrolled in the ALLHAT (Antihypertensive and Lipid-Lowering Treatment to Prevent Heart Attack Trial) study, chlorthalidone, a thiazide-type diuretic, reduced cardiovascular outcomes to an extent similar to lisinopril or amlodipine. ${ }^{55}$ However, diuretics may cause urinary electrolyte wasting and, secondary to this, hyponatremia, hypokalemia, and/or hypomagnesemia. Moreover, thiazide diuretics may cause metabolic disturbances, particularly at higher doses. Fortunately, the combination of RAS inhibitors with thiazide diuretics reduces both electrolyte and metabolic disturbances. Furthermore, when side effects are present they are generally mild to moderate in severity. ${ }^{6}$ At low doses, thiazide diuretics usually do not cause changes in renal function, and they can be used when the estimated glomerular filtration rate is $>30 \mathrm{~mL} /$ minute..$^{54,56}$

Several studies have analyzed the effects of the combination of RAS inhibitors and diuretics on renal outcomes. Thus, it has been shown that in hypertensive patients with stage 3-4 chronic kidney disease, the combination of losartan and hydrochlorothiazide significantly reduced the urinary protein-to-creatinine ratio, without significant changes in the serum creatinine levels and estimated glomerular filtration rates. Notably, none of the patients exhibited a significant increase in the occurrence of adverse effects. ${ }^{57}$ Similarly, in hypertensive patients with stage 3 chronic kidney disease, combination therapy with the maximum recommended daily dose of losartan of $100 \mathrm{mg}$ and a low dose of hydrochlorothiazide of $12.5 \mathrm{mg}$ ameliorated proteinuria and reduced BP more effectively than treatment with losartan $100 \mathrm{mg}$ alone, irrespective of whether the patients had diabetes. ${ }^{58}$ In a study that evaluated the changes in BP and urinary protein excretion in poorly controlled hypertensive and proteinuric patients with mild to moderate chronic kidney disease, patients were evaluated after switching from the high-dose ARBs to a combination of normal-dose telmisartan $(40 \mathrm{mg})$ and low-dose hydrochlorothiazide (12.5 mg). The combination of telmisartan and hydrochlorothiazide appeared to be more efficacious than a monotherapy of high-dose ARBs in reducing BP and urinary protein excretion. ${ }^{59}$

The PREMIER (Preterax in Albuminuria Regression) study compared the effects of the combination of perindopril $2 \mathrm{mg}$ and indapamide $0.625 \mathrm{mg}$ with the effects of enalapril monotherapy on albumin excretion rates in patients with type 2 diabetes, albuminuria, and hypertension in a 12-month, international, multicenter, randomized, double-blind, parallelgroup study. Although both treatments reduced BP, the fixed combination of perindopril and indapamide resulted in a greater, statistically significant fall in both BP $(\Delta$ systolic BP $-3.0 \mathrm{mmHg}, P=0.012 ; \Delta$ diastolic BP $-1.5 \mathrm{mmHg}$, $P=0.019)$ and albumin excretion rate $(-42 \%$ versus $-27 \%)$ than enalapril. Remarkably, the greater albumin excretion rate reduction remained significant after adjustment for mean BP (Table 3). ${ }^{60}$

The ADVANCE (Action in Diabetes and Vascular Disease: Preterax and Diamicron Modified-Release Controlled Evaluation) trial was performed to assess the effects of the fixed combination of perindopril and indapamide on serious vascular events in patients with diabetes, irrespective of initial BP levels or the use of other BP-lowering drugs. A total of 11,140 patients with type 2 diabetes were randomized to treatment with the fixed combination or matching placebo, in addition to current therapy. Compared with the patients assigned placebo, after a mean of 4.3 years of follow-up, those assigned to active therapy had a mean reduction in systolic BP of $5.6 \mathrm{mmHg}$ and diastolic BP of $2.2 \mathrm{mmHg}$. The relative risk of a major macrovascular or microvascular event was reduced by $9 \%$ (HR, 0.91; 95\% CI, 0.83-1.00; $P=0.04$ ). Active treatment was associated with a significant $21 \%$ reduction in all renal 
Table 3 Relevant studies of the effects of combining diuretics or calcium channel blockers with renin-angiotensin system inhibitors on renal outcomes

\begin{tabular}{|c|c|c|c|}
\hline Clinical setting & Study & Population & Commentary \\
\hline \multirow[t]{2}{*}{ Diuretics } & PREMIER $^{60}$ & $\begin{array}{l}\text { Patients with type } 2 \text { diabetes, } \\
\text { albuminuria, and hypertension }\end{array}$ & $\begin{array}{l}\text { The combination of perindopril and indapamide, when } \\
\text { compared with enalapril, resulted in a greater, statistically } \\
\text { significant fall in both } \mathrm{BP}(\Delta \text { systolic } \mathrm{BP}-3.0 \mathrm{mmHg}, P=0.0 \mathrm{I} \text {; } \\
\Delta \text { diastolic } \mathrm{BP}-\mathrm{I} .5 \mathrm{mmHg}, P=0.019) \text { and albumin excretion } \\
\text { rate }(-42 \% \text { vs }-27 \%)\end{array}$ \\
\hline & ADVANCE $^{61}$ & Patients with type 2 diabetes & $\begin{array}{l}\text { Those patients assigned to active treatment (perindopril- } \\
\text { indapamide) were associated with a significant reduction }(21 \%) \\
\text { in all renal events }(P<0.000 \mathrm{I}) \text {, with a trend in the reduction in } \\
\text { new or worsening nephropathy }(P=0.055) \text { and a significant } \\
\text { reduction in the development of microalbuminuria (relative risk } \\
\text { reduction, } 21 \% ; P<0.000 \mathrm{I})\end{array}$ \\
\hline \multirow[t]{4}{*}{$\begin{array}{l}\text { Calcium channel } \\
\text { blockers }\end{array}$} & $\mathrm{AMANDHA}^{66}$ & $\begin{array}{l}\text { Type } 2 \text { diabetic patients with } \\
\text { hypertension and microalbuminuria } \\
\text { uncontrolled with renin-angiotensin } \\
\text { system blockers }\end{array}$ & $\begin{array}{l}\text { Although manidipine and amlodipine decreased BP values to } \\
\text { a similar extent, urinary albumin excretion was more greatly } \\
\text { reduced with manidipine than with amlodipine }(65.5 \% \text { vs } \\
20 \% \text {, respectively, } P<0.0 \text { I at } 6 \text { months; } 62.7 \% \text { vs } 16.6 \% \text {, } \\
\text { respectively, } P<0.0 \text { I at the end of the extension phase } \\
\text { of } 18 \text { months) }\end{array}$ \\
\hline & CARTER $^{70}$ & $\begin{array}{l}\text { Hypertensive patients with } \\
\text { kidney disease }\end{array}$ & $\begin{array}{l}\text { After I year of treatment, despite a similar BP reduction, the } \\
\text { urinary protein-to-creatinine ratio significantly decreased in the } \\
\text { cilnidipine group compared with the amlodipine group }\end{array}$ \\
\hline & $\mathrm{DIAL}^{75}$ & $\begin{array}{l}\text { Hypertensive patients with } \\
\text { type } 2 \text { diabetes }\end{array}$ & $\begin{array}{l}\text { After } 9-12 \text { months of follow-up, both lercanidipine and ramipril } \\
\text { treatments resulted in a significant reduction in albumin } \\
\text { excretion rate without a statistically significant difference } \\
\text { between the two treatments }\end{array}$ \\
\hline & ACCOMPLISH ${ }^{78}$ & $\begin{array}{l}\text { Patients with hypertension and at } \\
\text { high risk for cardiovascular events }\end{array}$ & $\begin{array}{l}2.0 \% \text { of the benazepril plus amlodipine group vs } 3.7 \% \text { of } \\
\text { patients treated with the benazepril plus hydrochlorothiazide } \\
\text { showed chronic kidney disease progression }(\mathrm{HR}, 0.52 \\
P<0.000 \mathrm{I})\end{array}$ \\
\hline
\end{tabular}

Abbreviations: ACCOMPLISH, Avoiding Cardiovascular Events through Combination Therapy in Patients Living with Systolic Hypertension; ADVANCE, Action in Diabetes and Vascular Disease: Preterax and Diamicron Modified-Release Controlled Evaluation; AMANDHA, Efficacy and Tolerance Assessment of Manidipine in Type 2 Diabetic Patients with Hypertension and Microalbuminuria Uncontrolled with Renin-Angiotensin System Blockers; BP, blood pressure; CARTER, Cilnidipine versus Amlodipine Randomised Trial for Evaluation in Renal Desease; DIAL, Diabete, Ipertensione, Albuminuria, Lercanidipina; HR, hazard ratio; PREMIER, Preterax in Albuminuria Regression; vs, versus.

outcomes $(P<0.0001)$, with a trend in the reduction in new or worsening nephropathy $(3.3 \%$ versus $3.9 \%$; relative risk reduction, $18 \% ; P=0.055)$, and a significant reduction in the development of microalbuminuria (19.6\% versus $23.6 \%$; relative risk reduction, $21 \% ; P<0.0001$ ) (Table 3). ${ }^{61}$

In summary, volume excess has been shown to blunt the $\mathrm{BP}$ and albuminuria response to RAS inhibitors. Thus, acting on volume status by means of diuretic therapy effectively reduces BP and albuminuria. ${ }^{62}$ As a result, the combination of RAS inhibitors and diuretics seems to be particularly beneficial in hypertensive patients with renal disease.

\section{Combination of RAS inhibitors and calcium channel blockers}

Combining RAS inhibitors with a calcium channel blocker has been shown to effectively reduce BP values. ${ }^{1}$ Dihydropyridines are potent vasodilators that induce reflex activation of the RAS. As a result, the concomitant use of ACE inhibitors or ARBs may buffer this excessive activation. Furthermore, as calcium channel blockers raise angiotensin II levels, the antihypertensive effect of RAS inhibitors increases. ${ }^{63}$ Notably, the combination of calcium channel blockers with RAS inhibitors decreases the presence of drug-related side effects, particularly peripheral edema. ${ }^{64}$

Although through the reduction of BP levels calcium channel blockers may reduce urinary albumin excretion, not all calcium channel blockers are equal, as they differ in their effect on glomerular hemodynamics and urinary albumin excretion. ${ }^{54}$ Conventional dihydropyridines block only L-type calcium channels. This promotes peripheral vasodilatation, including afferent renal arterioles with little change in the efferent arteriole diameter, as the efferent arterioles lack L-type receptors. Consequently, there is an increase of intraglomerular pressure and, secondary to this, proteinuria. On the other hand, T-type calcium channel blockers are present in both afferent and efferent arterioles. Newer calcium channel blockers such as manidipine block both L- and T-type receptors, inducing vasodilatation not only 
in the glomerular afferent arteriole but also in the efferent arteriole, resulting in a reduction of proteinuria. ${ }^{54,65-67}$

Different studies have tested the effects of combining calcium channel blockers with RAS inhibitors. ${ }^{65,66,68-79}$ In a 12-week, double-blind study conducted in patients with hypertension and type 2 diabetes, patients were randomized either to a fixed-dose combination of amlodipine besylate and benazepril or to enalapril monotherapy. Although both treatments were similarly effective in lowering BP, reducing systemic vascular resistance, and decreasing urinary albumin excretion, those patients treated with combined therapy exhibited a significantly greater improvement in large-vessel compliance (52\% versus $32 \%$; $P<0.05) .{ }^{68}$ In a study comparing the long-term effect of amlodipine and fosinopril, either in monotherapy or in combination, on urinary albumin excretion, 453 hypertensive patients with type 2 diabetes and microalbuminuria were randomized to amlodipine (5-15 mg/day), fosinopril (10-30 mg/day), or amlodipine plus fosinopril (from $5 / 10$ to $15 / 30 \mathrm{mg}$ /day) for a 3-month titration period. The nonresponder patients or those complaining of side effects during the titration period were discontinued $(n=144)$; the remaining 309 patients were enrolled in the trial and were treated with the same therapy for 4 years. The combination therapy was more effective in reducing $\mathrm{BP}$ than either drug in monotherapy at any time of the study without affecting glucose homeostasis. Although the three treatment arms significantly reduced urinary albumin excretion during the 48-month study period, this effect was more pronounced and became evident earlier with fosinopril than with amlodipine monotherapy. Notably, the amlodipine-fosinopril combination provided a greater antialbuminuric effect than any of the monotherapies, but this could be because of the greater antihypertensive effects. ${ }^{69}$ The AMANDHA (Efficacy and Tolerance Assessment of Manidipine in Type 2 Diabetic Patients with Hypertension and Microalbuminuria Uncontrolled with Renin-Angiotensin System Blockers) study compared the efficacy and safety of adding manidipine $20 \mathrm{mg}$ versus amlodipine $10 \mathrm{mg}$ to the treatment of diabetic patients with uncontrolled hypertension and microalbuminuria despite full-dose treatment with a RAS blocker for at least 6 months. Although manidipine and amlodipine decreased BP values to a similar extent, urinary albumin excretion was more significantly reduced with manidipine than with amlodipine $(65.5 \%$ versus $20 \%$, respectively, $P<0.01$ at 6 months; $62.7 \%$ versus $16.6 \%$, respectively, $P<0.01$ at the end of the extension phase of 18 months) (Table 3). ${ }^{66}$ Cilnidipine is a dual L- and N-type calcium channel blocker that dilates both efferent and afferent arterioles. In the CARTER (Cilnidipine versus Amlodipine Randomised Trial for Evaluation in Renal Desease) study, nearly 340 patients with hypertension and kidney disease already receiving RAS inhibitor treatment were randomly assigned to cilnidipine or amlodipine. After 1 year of treatment, despite a similar BP reduction, the urinary proteinto-creatinine ratio significantly decreased in the cilnidipine group compared with the amlodipine group (Table 3 ). ${ }^{70}$

Lercanidipine is a dihydropyridine characterized by its high lipophilicity and selectivity for vascular smooth muscle, with a gradual and prolonged antihypertensive effect, as well as good tolerability, compared with other dihydropyridines. ${ }^{71-74}$ In the DIAL (Diabete, Ipertensione, Albuminuria, Lercanidipina) study, hypertensive patients with type 2 diabetes were treated with lercanidipine (10-20 mg/day) or ramipril (5-10 mg/day). After 9-12 months of follow-up, both lercanidipine and ramipril treatments resulted in a significant reduction in the albumin excretion rate without a statistically significant difference between the two treatment groups (Table 3). ${ }^{75}$ In a study that included 203 patients with chronic renal failure (creatinine $>1.4 \mathrm{mg} / \mathrm{dL}$ for males, creatinine $>1.2 \mathrm{mg} / \mathrm{dL}$ for females, or creatinine clearance $<70 \mathrm{~mL} /$ minute) who were all treated with RAS inhibitors (63.4\% with ACE inhibitors, 36.6\% with ARBs), lercanidipine showed a high antihypertensive effect, with a good tolerability profile. Notably, creatinine clearance improved from 41.8 to $45.8 \mathrm{~mL} /$ minute and proteinuria significantly decreased from 3.5 to $2.8 \mathrm{~g} /$ day. ${ }^{76}$ In a study that included 68 proteinuric ( $>500 \mathrm{mg} /$ day) patients, receiving ACE inhibitors $(51.4 \%)$ or ARBs (48.6\%) but with high BP, the addition of lercanidipine $20 \mathrm{mg}$ /day showed a high antihypertensive and antiproteinuric effect. This antiproteinuric effect seemed to be dose dependent and proportionally higher than BP reduction. $^{77}$

However, the most important trial performed in this context has been a substudy of the ACCOMPLISH (Avoiding Cardiovascular Events through Combination Therapy in Patients Living with Systolic Hypertension) trial. This study showed that initial antihypertensive therapy with benazepril plus amlodipine was superior to benazepril plus hydrochlorothiazide in reducing cardiovascular morbidity and mortality in 11,506 patients with hypertension who were at high risk for cardiovascular events. The effects of these drug combinations on progression of chronic kidney disease were assessed in this substudy. Progression of chronic kidney disease, a prespecified end point, was defined as the doubling of serum creatinine concentration or end-stage renal disease (estimated glomerular filtration 
rate $<15 \mathrm{~mL} /$ minute per $1.73 \mathrm{~m}^{2}$ of body surface area or the need for dialysis). The trial was prematurely stopped (mean follow-up of 2.9 years) because of the superior efficacy of benazepril plus amlodipine compared with benazepril plus hydrochlorothiazide. With regard to renal end points, $2.0 \%$ of the benazepril plus amlodipine group versus $3.7 \%$ of patients treated with benazepril plus hydrochlorothiazide showed chronic kidney disease progression (HR, 0.52; 95\% CI, $0.41-0.65 ; P<0.0001)$. With regard to side effects in patients with chronic kidney disease, while peripheral edema (33.7\% versus $16.0 \%$, for the benazepril plus amlodipine group and the benazepril plus hydrochlorothiazide group, respectively) and angioedema were more frequent in the benazepril plus amlodipine group, dizziness, hypokalemia, and hypotension were more frequent in the benazepril plus hydrochlorothiazide group (Table 3 ). ${ }^{78,79}$

\section{Dual blockade of the RAS}

Despite a complete RAS inhibition with ARBs or ACE inhibitors, a number of patients develop or experience progression of renal disease. ${ }^{1}$ As a result, several studies have investigated the effects of dual blockade of the RAS in renal outcomes. The CALM (Candesartan and Lisinopril Microalbuminuria) study aimed to assess and compare the effects of candesartan or lisinopril, or both, on BP and urinary albumin excretion in patients with microalbuminuria, hypertension, and type 2 diabetes. At 24 weeks the mean reduction in diastolic BP was significantly greater with combination treatment than with candesartan or lisinopril alone. Moreover, the reduction in urinary albumin-to-creatinine ratio was also greater with combination treatment, with a good tolerability profile. ${ }^{80}$ In a 12-month follow-up randomized, clinical trial, lisinopril $40 \mathrm{mg}$ once daily was compared with dual-blockade treatment with candesartan $16 \mathrm{mg}$ once daily and lisinopril $20 \mathrm{mg}$ once daily in diabetic patients aged 35-74 years. Reductions in systolic BP were similar in both groups $(6 \mathrm{mmHg}$ with dual blockade versus $2 \mathrm{mmHg}$ with lisinopril; $P=0.10$ ), with similar low rates of side effects. ${ }^{81}$

In a study comparing the efficacy of enalapril $5 \mathrm{mg}$, losartan $50 \mathrm{mg}$, or both in normotensive type 2 diabetic patients with microalbuminuria, the percentages of reduction in urinary albumin excretion rates at the end of 12 months were $58 \%, 59 \%$, and $60 \%$, respectively $(P=0.0001, P=0.0002$, $P=0.0003$, respectively; $P=0.346$ between groups). ${ }^{82}$ In a meta-analysis that studied the effects of dual blockade in the prevention of the progression of diabetic nephropathy, dual blockade was associated with a more marked proteinuria reduction $(P=0.01)$, a trend towards an increase in serum creatinine concentration $(6.86 \mu \mathrm{mol} / \mathrm{L} ; P=0.09)$, and an increase in potassium levels by $0.2 \mathrm{mmol} / \mathrm{L}(P<0.01){ }^{83}$

More recently, the ONTARGET study showed that the combination of telmisartan and ramipril, despite reducing BP by a few millimeters of mercury more than therapy with either ramipril or telmisartan, was associated with more adverse events without an increase in benefit. ${ }^{52}$ With regard to renal outcomes, the number of events for the composite primary outcome (dialysis, doubling of serum creatinine concentration, and death) was increased with combination therapy (HR, 1.09; 95\% CI, 1.01-1.18; $P=0.037$ ). The secondary renal outcome (dialysis or doubling of serum creatinine concentration) was also more frequent with combination therapy (HR, 1.24; 95\% CI, 1.01-1.51; $P=0.038) .{ }^{53}$ However, only approximately $4 \%$ of patients had overt proteinuria at baseline, and worsening of renal outcomes mostly occurred in the patients without baseline microproteinuria or frank proteinuria. As a result, these data can extend to patients with vascular disease or high-risk diabetes without heart failure, but they can hardly extend to patients with severe renal disease. ${ }^{27} \mathrm{~A}$ recent meta-analysis reported that there is a lack of evidence at present to support the use of combination therapy ${ }^{84}$ As reported in the AVOID trial, the dual blockade of RAS by aliskiren and losartan in hypertensive patients with type 2 diabetic nephropathy reduced the mean urinary albumin-to-creatinine ratio beyond BP control. ${ }^{40}$

\section{Conclusion}

To effectively reduce or at least slow the establishment and progression of renal disease in the hypertensive population it is crucial to attain BP goals. Although BP control rates have improved in recent years, mainly because of the increase in use of combined therapy, the fact is that many patients do not reach BP targets. ${ }^{33}$

As European guidelines indicate, all major antihypertensive drug classes (ACE inhibitors, ARBs, diuretics, calcium channel blockers, and beta-blockers) can be considered for treatment, including for diabetic patients. ${ }^{27}$ However, a number of studies have shown that treatment with ACE inhibitors, ARBs, and, more recently, aliskiren may provide beneficial effects beyond BP control, particularly in those with diabetes, microalbuminuria, or chronic kidney disease. As the majority of these patients will need at least two antihypertensive drugs to reach BP goals, the use of RAS inhibitors is a mandatory part of antihypertensive therapy in this population.

The best antihypertensive drugs to combine in this setting are diuretics and calcium channel blockers. Various studies have shown the benefits of combining RAS inhibitors with 
diuretics or calcium channel blockers in patients with renal disease. Canadian guidelines recommend the use of ACE inhibitors or ARBs as initial therapy in patients with diabetes and albuminuria and, when necessary to attain BP goals, thiazide diuretics (a loop diuretic should be considered if creatinine level is $>150 \mu \mathrm{mol} / \mathrm{L}$ ), cardioselective beta-blockers, or longacting calcium channel blockers can be added. ${ }^{29}$ In diabetic patients without albuminuria, Canadian guidelines indicate that ACE inhibitors, ARBs, dihydropyridine calcium channel blockers, or thiazide diuretics are adequate options for starting treatment; if the BP target is not achieved, these drugs can be combined, except ACE inhibitors and ARBs together. ${ }^{29}$ Finally, in subjects with nondiabetic chronic kidney disease with proteinuria, ACE inhibitors (ARBs if not tolerated) should be used as initial therapy, and diuretics as additive therapy. ${ }^{29}$

However, it is likely that new studies or new post hoc analyses may at least partly change these recommendations, clarifying the subgroups of patients who will benefit more from a combination with a diuretic or from a combination with a calcium channel blocker. To date, the RAS inhibitors recommended in this context are ACE inhibitors and ARBs. Aliskiren, the first available oral direct renin inhibitor, has shown promising results. Nonetheless, until the final results of the ALTITUDE (Aliskiren Trial in Type 2 Diabetes Using Cardiovascular and Renal Disease Endpoints) study (expected in 2012) are known, aliskiren could be used in hypertension, particularly in combination with other agents. ${ }^{27}$

\section{Disclosure}

The authors report no conflicts of interest in this work.

\section{References}

1. Mancia G, De Backer G, Dominiczak A, et al. 2007 Guidelines for the Management of Arterial Hypertension: the Task Force for the Management of Arterial Hypertension of the European Society of Hypertension (ESH) and of the European Society of Cardiology (ESC). J Hypertens. 2007;25(6):1105-1187.

2. Martínez-Castelao A, Górriz JL, Portolés JM, et al. Baseline characteristics of patients with chronic kidney disease stage 3 and stage 4 in Spain: the MERENA observational cohort study. BMC Nephrol. 2011;12:53.

3. Buckalew VM Jr, Berg RL, Wang SR, Porush JG, Rauch S, Schulman G. Prevalence of hypertension in 1,795 subjects with chronic renal disease: the modification of diet in renal disease study baseline cohort. Modification of Diet in Renal Disease Study Group. Am J Kidney Dis. 1996;28(6):811-821.

4. Deedwania PC. Hypertension and diabetes: new therapeutic options. Arch Intern Med. 2000;160(11):1585-1594.

5. Barrios V, Escobar C. Diabetes and hypertension: what is new? Minerva Cardioangiol. 2009;57(6):705-722.

6. Barrios V, Escobar C, Echarri R, de Alvaro F. New therapeutic progress in cardiorenal protection of the hypertensive patient with a focus on olmesartan. In: Volpe M, editor. Hot Topics in Hypertension. Vol 2. Modena, Italy: FB Communication; 2009(issue 8):1-24.
7. Graham I, Atar D, Borch-Johnsen K, et al. European guidelines on cardiovascular disease prevention in clinical practice: executive summary; Fourth Joint Task Force of the European Society of Cardiology and Other Societies on Cardiovascular Disease Prevention in Clinical Practice (constituted by representatives of nine societies and by invited experts). Eur Heart J. 2007;28(19):2375-2414.

8. Schiffrin EL, Lipman ML, Mann JF. Chronic kidney disease: effects on the cardiovascular system. Circulation. 2007;116(1):85-97.

9. Herzog CA, Ma JZ, Collins AJ. Poor long-term survival after acute myocardial infarction among patients on long-term dialysis. $N$ Engl $J$ Med. 1998;339(12):799-805.

10. Berl T, Henrich W. Kidney-heart interactions: epidemiology, pathogenesis, and treatment. Clin J Am Soc Nephrol. 2006;1(1):8-18.

11. García-Donaire JA, Ruilope LM. Cardiovascular and renal links along the cardiorenal continuum. Int J Nephrol. 2011;2011:975782.

12. Mann JF, Gerstein HC, Pogue J, Bosch J, Yusuf S. Renal insufficiency as a predictor of cardiovascular outcomes and the impact of ramipril: the HOPE randomized trial. Ann Intern Med. 2001;134(8):629-636.

13. Ruilope KM, Salvetti A, Jamerson K, et al. Renal function and intensive lowering of blood pressure in hypertensive participants of the Hypertension Optimal Treatment (HOT) study. J Am Soc Nephrol. 2001;12(2):218-225.

14. Tucker B, Fabbian F, Giles M, Thuraisingham RC, Raine AE, Baker LR. Left ventricular hypertrophy and ambulatory blood pressure monitoring in chronic renal failure. Nephrol Dial Transplant. 1997;12(4):724-728.

15. Barrios V, Escobar C, Murga N, et al. Clinical profile and management of hypertensive patients with chronic ischemic heart disease and renal dysfunction attended by cardiologists in daily clinical practice. J Hypertens. 2008;26(11):2230-2235.

16. Hillege HL, Fidler V, Diercks GF, et al. Urinary albumin excretion predicts cardiovascular and noncardiovascular mortality in general population. Circulation. 2002;106(14):1777-1782.

17. Romundstad S, Holmen J, Kvenild K, Hallan H, Ellekjær H. Microalbuminuria and all-cause mortality in 2,089 apparently healthy individuals: a 4.4-year follow-up study; the Nord-Trøndelag Health Study (HUNT), Norway. Am J Kidney Dis. 2003;42(3):466-473.

18. Wachtell $\mathrm{K}$, Ibsen $\mathrm{H}$, Olsen $\mathrm{MH}$, et al. Albuminuria and cardiovascular risk in hypertensive patients with left ventricular hypertrophy: the LIFE study. Ann Intern Med. 2003;139(11):901-906.

19. Sarafidis PA, Bakris GL. Microalbuminuria and chronic kidney disease as risk factors for cardiovascular disease. Nephrol Dial Transplant. 2006;21(9):2366-2374.

20. Hunsicker LG, Adler S, Caggiula A, et al. Predictors of the progression of renal disease in the Modification of Diet in Renal Disease study. Kidney Int. 1997;51(6):1908-1919.

21. Morales E, Valero MA, León M, Hernández E, Praga M. Beneficial effects of weight loss in overweight patients with chronic proteinuric nephropathies. Am J Kidney Dis. 2003;41(2):319-327.

22. Hsu CY, McCulloch CE, Darbinian J, Go AS, Iribarren C. Elevated blood pressure and risk of end-stage renal disease in subjects without baseline kidney disease. Arch Intern Med. 2005;165(8):923-928.

23. Klag MJ, Whelton PK, Randall BL, et al. Blood pressure and end-stage renal disease in men. $N$ Engl J Med. 1996;334(1):13-18.

24. Reynolds K, Gu D, Muntner P, et al. A population-based, prospective study of blood pressure and risk for end-stage renal disease in China. J Am Soc Nephrol. 2007;18(6):1928-1935.

25. Bakris GL, Williams M, Dworkin L, et al. Preserving renal function in adults with hypertension and diabetes: a consensus approach. Am J Kidney Dis. 2000;36(3):646-661.

26. Jafar TH, Stark PC, Schmid CH, et al. Progression of chronic kidney disease: the role of blood pressure control, proteinuria, and angiotensinconverting enzyme inhibition: a patient-level meta-analysis. Ann Intern Med. 2003;139(4):244-252.

27. Mancia G, Laurent S, Agabiti-Rosei E, et al. Reappraisal of European guidelines on hypertension management: a European Society of Hypertension Task Force document. J Hypertens. 2009;27(11):2121-2158. 
28. National Institute for Health and Clinical Excellence. Type 2 diabetes: the management of type 2 diabetes. London: NICE; 2009. Available from: http://www.nice.org.uk/guidance/CG87.

29. Hackam DG, Khan NA, Hemmelgarn BR, et al. The 2010 Canadian Hypertension Education Program recommendations for the management of hypertension: part 2. Therapy. Can J Cardiol. 2010;26(5):249-258.

30. Upadhyay A, Earley A, Haynes SM, Uhlig K. Systematic review: blood pressure target in chronic kidney disease and proteinuria as an effect modifier. Ann Intern Med. 2011;154(8):541-548.

31. Barrios V, Banegas JR, Ruilope LM, Rodicio JL. Evolution of blood pressure control in Spain. J Hypertens. 2007;25(9):1975-1977.

32. Barrios V, Escobar C, Calderón A, et al. Blood pressure and lipid goal attainment in the hypertensive population in the primary care setting in Spain. J Clin Hypertens (Greenwich). 2007;9(5):324-329.

33. Escobar C, Barrios V. Combined therapy in the treatment of hypertension. Fundam Clin Pharmacol. 2010;24(1):3-8.

34. Volpe M. Angiotensin II: an amplifier of cardiovascular risk. Curr Hypertens Rep. 2004;6(4):247-248.

35. Schmieder RE, Ruilope LM, Barnett AH. Renal protection with angiotensin receptor blockers: where do we stand. J Nephrol. 2011;24(5):569-580.

36. Brewster UC, Perazella MA. The renin-angiotensin-aldosterone system and the kidney: effects on kidney disease. Am J Med. 2004;116(4):263-272.

37. Fliser D. Perspectives in renal disease progression: the endothelium as a treatment target in chronic kidney disease. $J$ Nephrol. 2010;23(4):369-376.

38. Campbell DJ, Woodward M, Chalmers JP, et al. Prediction of myocardial infarction by $\mathrm{N}$-terminal-pro-B-type natriuretic peptide, $\mathrm{C}$-reactive protein, and renin in subjects with cerebrovascular disease. Circulation. 2005;112(1):110-116.

39. Schmieder RE, Hilgers KF, Schlaich MP, Schmidt BM. Renin-angiotensin system and cardiovascular risk. Lancet. 2007;369(9568):1208-1219.

40. Parving HH, Persson F, Lewis JB, Lewis EJ, Hollenberg NK; AVOID Study Investigators. Aliskiren combined with losartan in type 2 diabetes and nephropathy. N Engl J Med. 2008;358(23):2433-2446.

41. Ruggenenti P, Fassi A, Ilieva AP, et al. Preventing microalbuminuria in type 2 diabetes. $N$ Engl J Med. 2004;351(19):1941-1951.

42. Haller H, Ito S, Izzo JL Jr, et al. Olmesartan for the delay or prevention of microalbuminuria in type 2 diabetes. $N$ Engl J Med. 2011;364(10):907-917.

43. Effects of ramipril on cardiovascular and microvascular outcomes in people with diabetes mellitus: results of the HOPE study and MICRO-HOPE substudy. Heart Outcomes Prevention Evaluation Study Investigators. Lancet. 2000;355(9200):253-259.

44. Parving HH, Lehnert H, Bröchner-Mortensen J, et al. The effect of irbesartan on the development of diabetic nephropathy in patients with type 2 diabetes. N Engl J Med. 2001;345(12):870-878.

45. Brenner BM, Cooper ME, de Zeeuw D, et al. Effects of losartan on renal and cardiovascular outcomes in patients with type 2 diabetes and nephropathy. $N$ Engl J Med. 2001;345(12):861-869.

46. Lewis EJ, Hunsicker LG, Clarke WR, et al. Renoprotective effect of the angiotensin-receptor antagonist irbesartan in patients with nephropathy due to type 2 diabetes. $N$ Engl J Med. 2001;345(12):851-860.

47. Imai E, Chan JC, Ito S, et al. Effects of olmesartan on renal and cardiovascular outcomes in type 2 diabetes with overt nephropathy: a multicentre, randomised, placebo-controlled study. Diabetologia. 2011;54(12):2978-2986.

48. Barrios V, Escobar C. Aliskiren in the management of hypertension. Am J Cardiovasc Drugs. 2010;10(6):349-358.

49. Asselbergs FW, Diercks GF, Hillege HL, et al. Effects of fosinopril and pravastatin on cardiovascular events in subjects with microalbuminuria. Circulation. 2004;110(18):2809-2816.

50. Randomised placebo-controlled trial of effect of ramipril on decline in glomerular filtration rate and risk of terminal renal failure in proteinuric, non-diabetic nephropathy: the GISEN Group (Gruppo Italiano di Studi Epidemiologici in Nefrologia). Lancet. 1997;349(9069):1857-1863.
51. Hou FF, Xie D, Zhang X, et al. Renoprotection of Optimal Antiproteinuric Doses (ROAD) study: a randomized controlled study of benazepril and losartan in chronic renal insufficiency. J Am Soc Nephrol. 2007;18(6):1889-1898.

52. ONTARGET Investigators, Yusuf S, Teo KK, et al. Telmisartan, ramipril, or both in patients at high risk for vascular events. $N$ Engl J Med. 2008;358(15):1547-1559.

53. Mann JF, Schmieder RE, McQueen M, et al. Renal outcomes with telmisartan, ramipril, or both, in people at high vascular risk (the ONTARGET study): a multicentre, randomised, double-blind, controlled trial. Lancet. 2008;372(9638):547-553.

54. Reboldi G, Gentile G, Angeli F, Verdecchia P. Choice of ACE inhibitor combinations in hypertensive patients with type 2 diabetes: update after recent clinical trials. Vasc Health Risk Manag. 2009;5(1):411-427.

55. Whelton PK, Barzilay J, Cushman WC, et al. Clinical outcomes in antihypertensive treatment of type 2 diabetes, impaired fasting glucose concentration, and normoglycemia: Antihypertensive and LipidLowering Treatment to Prevent Heart Attack Trial (ALLHAT). Arch Intern Med. 2005;165(12):1401-1409.

56. Palmer BF. Renal dysfunction complicating the treatment of hypertension. N Engl J Med. 2002;347(16):1256-1261.

57. Abe M, Okada K, Maruyama T, Matsumoto K. Renoprotect and blood pressure lowering effect of low-dose hydrochlorothiazide added to intensive renin-angiotensin inhibition in hypertensive patients with chronic kidney disease. Int J Clin Pharmacol Ther. 2009;47(8):525-532.

58. Abe M, Okada K, Maruyama T, Matsumoto K. Antiproteinuric and blood pressure-lowering effects of a fixed-dose combination of losartan and hydrochlorothiazide in hypertensive patients with stage 3 chronic kidney disease. Pharmacotherapy. 2009;29(9):1061-1072.

59. Abe M, Okada K, Maruyama T, Matsumoto S, Matsumoto K. Blood pressure-lowering and antiproteinuric effect of switching from highdose angiotensin receptor blockers to normal-dose telmisartan and low-dose hydrochlorothiazide in hypertensive patients with chronic kidney disease. Int J Clin Pharmacol Ther. 2010;48(3):206-213.

60. Mogensen CE, Viberti G, Halimi S, et al. Effect of low-dose perindopril/indapamide on albuminuria in diabetes: preterax in albuminuria regression: PREMIER. Hypertension. 2003;41(5):1063-1071.

61. Patel A; ADVANCE Collaborative Group, MacMahon S, et al. Effects of a fixed combination of perindopril and indapamide on macrovascular and microvascular outcomes in patients with type 2 diabetes mellitus (the ADVANCE trial): a randomised controlled trial. Lancet. 2007;370(9590):829-840.

62. Heerspink HJ. Therapeutic approaches in lowering albuminuria: travels along the renin-angiotensin-aldosterone-system pathway. Adv Chronic Kidney Dis. 2011;18(4):290-299.

63. Gojanovic B, Feihl F, Liaudet L, Waeber B. Concomitant calcium entry blockade and inhibition of the renin-angiotensin system: a rational and effective means for treating hypertension. J Renin Angiotensin Aldosterone Syst. 2008;9(1):1-9.

64. Messerli FH. Vasodilatory edema: a common side effect of antihypertensive therapy. Curr Cardiol Rep. 2002;4(6):479-482.

65. Galceran J, Plana J, Felip A, Pou G, Vila J, Sobrino J. Manidipine treatment in patients with albuminuria not sufficiently reduced with renin-angiotensin system blockers. Expert Rev Cardiovasc Ther. 2010;8(6):751-757.

66. Martinez-Martin FJ, Saiz-Satjes M. Add-on manidipine versus amlodipine in diabetic patients with hypertension and microalbuminuria: the AMANDHA study. Expert Rev Cardiovasc Ther. 2008;6(10):1347-1355.

67. Hayashi K, Wakino S, Sugano N, Ozawa Y, Homma K, Saruta T. $\mathrm{Ca} 2+$ channel subtypes and pharmacology in the kidney. Circ Res. 2007;100(3):342-353.

68. Winer N, Folker A, Murphy JA, et al. Effect of fixed-dose ACE-inhibitor/ calcium channel blocker combination therapy vs ACE-inhibitor monotherapy on arterial compliance in hypertensive patients with type 2 diabetes. Prev Cardiol. 2005;8(2):87-92. 
69. Fogari R, Preti P, Zoppi A, et al. Effects of amlodipine fosinopril combination on microalbuminuria in hypertensive type 2 diabetic patients. Am J Hypertens. 2002;15(12):1042-1049.

70. Fujita T, Ando K, Nishimura H, et al. Antiproteinuric effect of the calcium channel blocker cilnidipine added to renin-angiotensin inhibition in hypertensive patients with chronic renal disease. Kidney Int. 2007;72(12):1543-1549.

71. Egan CG, Pontremoli R. Role of the fixed-dose combination lercanidipine-enalapril in renal protection. J Nephrol. 2011;24(4): 428-437.

72. Barrios V, Navarro A, Esteras A, et al. Antihypertensive efficacy and tolerability of lercanidipine in daily clinical practice: the ELYPSE study; Eficacia de Lercanidipino y su Perfil de Seguridad. Blood Press. 2002;11(2):95-100.

73. Barrios V, Escobar C, de la Figuera M, et al. Tolerability of high doses of lercanidipine versus high doses of other dihydropyridines in daily clinical practice: the TOLERANCE study. Cardiovasc Ther. 2008;26(1):2-9.

74. Barrios V, Escobar C, Navarro A, et al. Lercanidipine is an effective and well tolerated antihypertensive drug regardless the cardiovascular risk profile: the LAURA study. Int J Clin Pract. 2006;60(11):1364-1370.

75. Dalla Vestra M, Pozza G, Mosca A, et al. Effect of lercanidipine compared with ramipril on albumin excretion rate in hypertensive type 2 diabetic patients with microalbuminuria: DIAL study (diabete ipertensione, albuminuria, lercanidipina). Diabetes Nutr Metab. 2004; 17(5):259-266.

76. Robles NR, Ocon J, Gomez CF, et al. Lercanidipine in patients with chronic renal failure: the ZAFRA study. Ren Fail. 2005;27(1):73-80.

77. Robles NR, Romero B, de Vinuesa EG, Sánchez-Casado E, Cubero JJ. Treatment of proteinuria with lercanidipine associated with reninangiotensin axis-blocking drugs. Ren Fail. 2010;32(2):192-197.
78. Bakris GL, Sarafidis PA, Weir MR, et al. Renal outcomes with different fixed-dose combination therapies in patients with hypertension at high risk for cardiovascular events (ACCOMPLISH): a prespecified secondary analysis of a randomised controlled trial. Lancet. 2010; 375(9721):1173-1181.

79. Barrios V, Escobar C. Antihypertensive and organ-protective effects of benazepril. Expert Rev Cardiovasc Ther. 2010;8(12):1653-1671.

80. Mogensen CE, Neldam S, Tikkanen I, et al. Randomised controlled trial of dual blockade of renin-angiotensin system in patients with hypertension, microalbuminuria, and non-insulin dependent diabetes: the candesartan and lisinopril microalbuminuria (CALM) study. BMJ. 2000;321(7274):1440-1444.

81. Andersen NH, Poulsen PL, Knudsen ST, et al. Long-term dual blockade with candesartan and lisinopril in hypertensive patients with diabetes: the CALM II study. Diabetes Care. 2005;28(2):273-277.

82. Tütüncü NB, Gürlek A, Gedik O. Efficacy of ACE inhibitors and ATII receptor blockers in patients with microalbuminuria: a prospective study. Acta Diabetol. 2001;38(4):157-161.

83. Jennings DL, Kalus JS, Coleman CI, Manierski C, Yee J. Combination therapy with an ACE inhibitor and an angiotensin receptor blocker for diabetic nephropathy: a meta-analysis. Diabet Med. 2007;24(5): 486-493.

84. Maione A, Navaneethan SD, Graziano G, et al. Angiotensin-converting enzyme inhibitors, angiotensin receptor blockers and combined therapy in patients with micro- and macroalbuminuria and other cardiovascular risk factors: a systematic review of randomized controlled trials. Nephrol Dial Transplant. 2011;26(9):2827-2847.

\section{Publish your work in this journal}

The International Journal of Nephrology and Renovascular Disease is an international, peer-reviewed open-access journal focusing on the pathophysiology of the kidney and vascular supply. Epidemiology, screening, diagnosis, and treatment interventions are covered as well as basic science, biochemical and immunological studies. The journal welcomes original research, clinical studies, reviews \& evaluations, expert opinion and commentary, case reports and extended reports. The manuscript management system is completely online and includes a very quick and fair peerreview system, which is all easy to use. Visit http://www.dovepress.com/ testimonials.php to read real quotes from published authors. 